\title{
BACTERIOLOGICAL PROFILE AND ANTIMICROBIAL SUSCEPTIBILITY PATTERNS OF BLOOD CULTURE ISOLATES AMONG FEBRILE PATIENTS IN A TERTIARY CARE HOSPITAL, BANGLADESH
}

\author{
IQBAL $\mathrm{H}^{1}$, MAHBOOB N ${ }^{2}$, AHMED $\mathrm{M}^{3}$, MAMUN $\mathrm{KZ}^{4}$, RAHIM A ${ }^{5}$, AZAD KAK $^{6}$
}

\begin{abstract}
Background: Bacterial bloodstream infections (BSI) are a major problem for health care personnel's, which leads to high morbidity and mortality of patients. Early and timely diagnosis and appropriate medication will be the best way to save the lives of affected ones.

Aim: The aim of the present study was to determine the bacterial profile of bloodstream infections and their antibiotic susceptibility pattern.

Methods: This descriptive cross-sectional study was carried out at the Microbiology Laboratory, Popular diagnostic Ltd, Dhanmondi, Dhaka over a three months periods, from November' 2017 to January' 2018. A total 822 blood culture samples were screened. The positive blood cultures were examined and the organisms were identified as per standard procedures. Antimicrobial susceptibility testing was performed for all isolates by using disk diffusion technique, according to CLSI guidelines 27.
\end{abstract}

Results: From total blood culture samples, 105 (12.77\%) were positive. The most common isolated pathogens were Salmonella Typhi, 59 (56.19.5\%). Other isolates are Salmonella paratyphi A \& B, 11(10.47\%); Eschericia coli 14 (13.33\%); Klebsiella spp, 05(04.76\%); Acinetobacter spp. 11 (10.47\%) Enterococcus spp. 02 (01.90\%); Staphylococcus aureus, 02 (01.90\%) and one Candida spp (0.95\%). S. Typhi showed 100\% sensitivity against Ceftriaxone and Cefixime, and also more than $80 \%$ sensitive against first-line drugs (Chloramphenicol and Co-trimoxazole). Almost all the strains were found resistant towards Nalidixic acid (sensitivity 05.71\%). Most of the Staphylococcus aureus and Enterococcus spp were susceptible to Vancomycin and Linezolid. More than $80 \%$ of E. coli and Klebsiella spp.are sensitive to Imipenem and Meropenem and least sensitivity show against Ciprofloxacin, Cephradine and Ceftriaxone.

Conclusion: Ongoing surveillance for antimicrobial susceptibility remains essential, and will enhance efforts to identify resistance and attempt to limit its spread.

Key words: Bloodstream infections, Automated blood culture, Antimicrobial susceptibility.

J Dhaka Med Coll. 2018; 27(2) : 114-122

\section{Introduction}

Invasion of the bloodstream by microorganisms constitutes one of the most serious situations in infectious disease ${ }^{1}$. It remains one of the most important causes of morbidity and mortality globally ${ }^{2}$ and is the most common healthcareassociated infections ${ }^{3}$.
The blood culture represents a critical tool for the detection of bloodstream infections. Despite its limitations, the blood culture remains the "gold standard" for the detection of bacteremia 4 . It also provides essential information for the evaluation of a variety of diseases like

1. Dr. Hasina Iqbal, MPhil (Microbiology), Assistant Professor, Department of Microbiology, Popular Medical College, Dhaka.

2. Dr. Nabeela Mahboob, MD (Virology), Lecturer, Department of Microbiology, Popular Medical College, Dhaka.

3. Dr. Mushtaque Ahmed, MPhil (Virology), FCPS (Microbiology), Professor Department of Microbiology, Popular Medical College, Consultant, Popular diagnostic Centre Ltd, Dhanmondi, Dhaka

4. Dr. Kazi Zulfiquer Mamun, MSc (Tropical Medicine, UK), PhD (UK), Professor and Head of the Department of Microbiology, Popular Medical College, Dhaka

5. Dr. Abdur Rahim, RP Medicine, Shaheed Suhrawardy Medical College, Dhaka

6. Prof. Khan Abul Kalam Azad, Professor \& Head, Department of Medicine, Dhaka Medical College, Dhaka

Correspondence : Dr. Mushtaque Ahmed, Professor, Department of Microbiology, Popular Medical College, Consultant, Popular diagnostic Centre Limited, Dhanmondi, Dhaka, Email: mushtaque_nasba@yahoo.com, Contact no.: 01711739239 Received: 12 May 2018

Revision: 26 August 2018

Accepted: 08 September 2018

https://doi.org/10.3329/jdmc.v27i2.45820 
endocarditis, pneumonia, and pyrexia of unknown origin and particularly, in patients with suspected sepsis ${ }^{5}$. An accurate interpretation of culture results is critical not only from the perspective of individual patient care but also from the standpoint of hospital epidemiology and public health ${ }^{4}$.

Many bacteria have been reported which cause bacteraemia with variation in distribution from place to place ${ }^{6}$. Salmonella enterica serotype Typhi, Staphylococcus aureus, Escherichia coli, and other Gram-negative organisms are regarded as the leading causes of $\mathrm{BSI}^{7}$. Among them, antibiotic resistant strains are emerging with great speed, causing a deep concern to the medical fraternity, and present therapeutic challenges ${ }^{8}$. Such infections result in longer hospital stay, higher costs and death as compared to antibiotic susceptible bacteria 9 . Appropriate antimicrobial therapy has been shown to reduce mortality among patients with gram negative bacteremia and, when initiated early, in critically ill patients with bacteremia ${ }^{10}$.

Researches in various countries revealed that there is high bacterial drug resistance to commonly used antibiotics mainly due to the lack of national guideline for antibiotic use in some developing countries. There is also absence of good laboratory facilities to do antimicrobial drug susceptibility test. As a result clinicians use empirical way to treat their patients. There is also high self treatment of humans, and animals without prescription of doctors. These all lead to emergence and rapid dissemination of resistance ${ }^{2}$.

In Bangladesh there are only a few studies on organisms involved in bloodstream bacterial infection and their susceptibility pattern. Since the antibiotic resistance pattern can vary with the geographical region, this study is undertaken to determine the common bacterial agents associated with bacteraemia and their antimicrobial susceptibility patterns in febrile patients attending Popular Medical College.

\section{Methods}

Study design, study area and sampling process This descriptive cross-sectional study was carried out at the Microbiology Laboratory,
Popular diagnostic Ltd, Dhanmondi, Dhaka over a three months periods, from November'2017 to January' 2018. During this period, total 822 blood samples with suspected bacteremia and history of febrile illness from adult and children (below 18 years) were included.

\section{Data collection and laboratory procedures}

About $10 \mathrm{ml}$ of venous blood for adults and $3 \mathrm{ml}$ for children was collected aseptically using $70 \%$ alcohol and $2 \%$ tincture of iodine and transferred into a BD BACTEC ${ }^{\mathrm{TM}}$ bottle. Blood culture broths were then incubated in the automated BD BACTEC ${ }^{\mathrm{TM}}$ system at $37^{\circ} \mathrm{C}$ for 72 hours.

\section{Bacterial identification}

The preliminary signal of bacterial growth in BD BACTEC ${ }^{\text {TM }}$ bottle was detected. Specific identification of all culture positive samples was accomplished by immediate Gram staining. Then sub-culture was done on Blood agar, Chocolate agar and MacConkeys agar media (OXOID CO. UK). Inoculated Blood agar and MacConkeys agar plates were incubated aerobically at $37^{\circ} \mathrm{C}$. The Chocolate agar plates were incubated at $37^{\circ} \mathrm{C}$ under $5-10 \% \mathrm{CO} 2$ condition (Candle jar) and examined after 1824 hours of incubation.

Bacterial isolates were identified by Colony morphology, Gram staining reaction, biochemical tests using Catalase test, Coagulase test, Oxidase test, Triple Sugar Iron agar (TSI) (OXOID, UK), Citrate utilization test $\left(\mathrm{BBL}^{\mathrm{TM}}\right)$,Urease test $\left(\mathrm{BBL}^{\mathrm{TM}}\right)$ and Motility Indole Urea (MIU) (BBLTM) test and use of antisera for Salmonella for the standard procedure for bacterial identification ${ }^{11}$.

Blood culture broths that did not generate any signal within 72 hours of incubation were subcultured before being reported as a negative result.

\section{Antimicrobial susceptibility test}

Antimicrobial susceptibility test was carried out by the Kirby-Bauer disc diffusion method using Mueller-Hinton agar (MHA) media according to Clinical Laboratory Standards Institute (CLSI) guidelines $27^{12}$ and antibiotic disc from OXOID $\mathrm{CO}$. Minimum distance of the disc were $24 \mathrm{~mm}$ from center to center. Zone of inhibition were measured in millimeters after 24 hours of incubation. 
Based on the zone of inhibition obtained, the isolates were classified into sensitive, intermediate, and resistant pattern.

For each separate group of organisms separate set of antimicrobials were used. The antibiotics discs and their concentrations were as follows:

Amoxyclav (20/10 mcg), Co-trimoxazoleb (1.25/ $23.75 \mathrm{mcg})$, Chloramphenicol (30 mcg), Ciprofloxacin $(5 \mathrm{mcg})$, Levofloxacin $(5 \mathrm{mcg})$, Nalidixic acid $(30 \mathrm{mcg})$, Ceftriaxone $(30 \mathrm{mcg})$, Cefixime $(5 \mathrm{mcg})$ for $\mathrm{S}$. Typhi and $\mathrm{S}$. paratyphi.

Co-trimoxazole (1.25/23.75 mcg), Gentamicin (10 mcg), Ciprofloxacin (5mcg), Levofloxacin (5mcg), Cephradine (30 mcg), Cefoxitin (30 mcg), Ceftriaxone $(30 \mathrm{mcg})$, Ceftazidime $(30 \mathrm{mcg})$,

Cefepime (30 mcg), Aztreonam (30 mcg), Imipenem (10 mcg), Meropenem (10 mcg), Netilmicin (30 mcg) for E. coli and Klebsiella spp.

Amikacin (30 mcg), Ciprofloxacin $(5 \mathrm{mcg})$, Levofloxacin $(5 \mathrm{mcg})$, Ceftriaxone $(30 \mathrm{mcg})$, Ceftazidime (30 mcg), Cefepime (30 mcg), Aztreonam (30 $\mathrm{mcg})$, Imipenem $(10 \mathrm{mcg})$, Meropenem (10 mcg), PiperacillinTazobactum(100/10mcg) for Acinetobacter spp.

Ciprofloxacin (5mcg), Levofloxacin (5mcg), Ampicillin (10 mcg), Penicillin (10 mcg), Gentamicin (10 mcg), Vancomycin (30 mcg), Linezolid (30mcg) for Enterococcus spp.

Amikacin (30 mcg), Cephradine (30 mcg), Cefoxitin (30 mcg), Cefepime (30 mcg), Cloxacillin $(5 \mathrm{mcg})$, Gentamicin $(10 \mathrm{mcg})$, Vancomycin (30mcg), Linezolid (30 mcg) for $S$. aureus.

\section{Quality control}

Reference strains E. coli (ATCC 25922) and S. Aureus (ATCC 25923) were used as a control reference strains for identifications and drug susceptibility testing. Negative control was done by randomly taking the prepared culture media and incubating over night to see for any growth.

\section{Data analysis}

SPSS version 20 software was used for statistical analysis. Chi square test $\left(\div^{2}\right)$ was used to determine relationship between dependent and independent variable. $P$ value $<0.05$ was used to indicate significant association.

\section{Results}

From the total 822 febrile patients, 105 (12.77 $\%)$ were culture positive, 717 (87.22\%) were negative (Table I). Among 105 culture positive patients $68(71.40 \%)$ were males and 37 $(38.85 \%)$ were females. Their age ranges from 1 day -80 years [mean $26.326 \pm 19.506$ (SD)]. Predominant isolates were Salmonella Typhi, $59(56.19 \%)$ followed by S. paratyphi $A \& B$ $11(10.47 \%)$, Escherechia coli 14(13.33), Acinetobacter spp 11(10.47), Klebsiella spp 05(04.76), Staph aureus 02(01.90), and Enterococcus spp 02(01.90), Candida spp 01(00.95). (Table IV).

In culture positive samples, $60(57.14 \%)$ were adult and 45 (42.85\%) were children (Table II). There were 68 (71.40\%) males and 37 (38.85\%) females, as shown in (Table III).

Antibiotic susceptibility patterns of bacterial isolates are elaborated in (Table V), (Table VI), (Table VII) (Table VIII) and (Table IX).

\section{Table-I}

Rate of culture positive and negative samples

\begin{tabular}{|c|c|c|}
\hline Results of culture & $\begin{array}{c}\text { Frequency } \\
(\mathrm{N}=822)\end{array}$ & $\begin{array}{c}\text { Percentage } \\
(\%)\end{array}$ \\
\hline $\begin{array}{l}\text { Growth of bacteria } \\
\text { (Positive) }\end{array}$ & 105 & 12.77 \\
\hline No growth (Negative) & 717 & 87.22 \\
\hline Total & 822 & 100 \\
\hline
\end{tabular}

\begin{tabular}{|c|c|c|}
\hline$\overline{\text { Age }}$ & $\begin{array}{c}\text { Frequency } \\
(\mathrm{n}=105)\end{array}$ & $\begin{array}{c}\text { Percentage } \\
\text { (\%) }\end{array}$ \\
\hline Adult & 60 & 57.14 \\
\hline Children* & 45 & 42.85 \\
\hline Total & 105 & 100 \\
\hline
\end{tabular}

* Age below 18 years

Table - III

Distribution of sex in culture positive specimens

\begin{tabular}{lcc}
\hline Sex & Frequency $(\mathrm{n}=105)$ & Percentage $(\%)$ \\
\hline Male & 68 & 71.40 \\
Female & 37 & 38.85 \\
\hline Total & 105 & 100 \\
\hline
\end{tabular}


Table - IV

Distribution of isolated pathogens

\begin{tabular}{lcc}
\hline Pathogens & Frequency $(\mathrm{n}=105)$ & Percentages $(\%)$ \\
\hline Salmonella typhi & 59 & 56.19 \\
Salmonella paratyphi A\&B & 11 & 10.47 \\
Escherichia coli & 14 & 13.33 \\
Staphylococcus aureus & 02 & 01.90 \\
Acinetobacter spp. & 11 & 10.47 \\
Klebsiella spp. & 05 & 04.76 \\
Enterococcus & 02 & 01.90 \\
Candida species & 01 & 00.95 \\
\hline Total & 105 & 100 \\
\hline
\end{tabular}

Table V

Antibiotic sensitivity of Salmonella (S. Typhi and S. paratyphi)

\begin{tabular}{|c|c|c|c|c|c|c|c|c|}
\hline \multirow[t]{2}{*}{ Antibiotic } & \multirow{2}{*}{$\begin{array}{c}\text { Disc content } \\
\text { mcg }\end{array}$} & \multicolumn{2}{|c|}{ S. Typhi (59) } & \multicolumn{2}{|c|}{ S. paratyphi A \& B (11) } & \multirow{2}{*}{$\begin{array}{c}\text { Sensitive } \\
\geq \mathrm{mm}\end{array}$} & \multirow{2}{*}{$\begin{array}{c}\text { Inter } R \\
\text { mediate } \\
(\mathrm{mm})\end{array}$} & \multirow{2}{*}{$\begin{array}{l}\text { Resistance } \\
\quad \geq \mathrm{mm}\end{array}$} \\
\hline & & Sensitive & Resistant & Sensitive & Resistant & & & \\
\hline \multirow[t]{2}{*}{ Amox-clav } & $20 / 10$ & 39 & 20 & 11 & ------ & 18 & $14-17$ & 13 \\
\hline & & $(66.10 \%)$ & $(33.89 \%)$ & $(100 \%)$ & & & & \\
\hline \multirow[t]{2}{*}{ Co-trimoxazole } & $1.25 /$ & 50 & 09 & 11 & ------ & 16 & $11-15$ & 10 \\
\hline & 23.75 & $(84.74 \%)$ & $(15.25 \%)$ & $(100 \%)$ & & & & \\
\hline \multirow[t]{2}{*}{ Chloramphenicol } & 30 & 50 & 09 & 11 & ------ & 18 & $13-17$ & 8 \\
\hline & & $(84.74 \%)$ & $(15.25 \%)$ & $(100 \%)$ & & & & \\
\hline \multirow[t]{2}{*}{ Ciprofloxacin } & 5 & *45 & 14 & 11 & ------ & 31 & $21-30$ & 20 \\
\hline & & $(76.27 \%)$ & $(23.72 \%)$ & $(100 \%)$ & & & & \\
\hline \multirow[t]{2}{*}{ Levofloxacin } & 5 & *45 & 14 & 11 & ------- & 31 & $21-30$ & 20 \\
\hline & & $(76.27 \%)$ & $(23.72 \%)$ & $(100 \%)$ & & & & \\
\hline \multirow[t]{2}{*}{ Nalidixic acid } & 30 & 06 & 53 & ------ & 11 & 19 & $14-18$ & 13 \\
\hline & & $(5.71 \%)$ & $(89.83 \%)$ & & $(100 \%)$ & & & \\
\hline \multirow[t]{2}{*}{ Ceftriaxone } & 30 & 59 & ------ & 11 & ------- & 23 & $20-22$ & 19 \\
\hline & & $(100 \%)$ & & $(100 \%)$ & & & & \\
\hline \multirow[t]{2}{*}{ Cefixime } & 5 & 59 & ------ & 11 & ------ & 19 & $16-18$ & 15 \\
\hline & & $(100 \%)$ & & $(100 \%)$ & & & & \\
\hline
\end{tabular}

* I=Intermediate sensitive 
Table VI

Antibiotic sensitivity of E.coli and Klebsiella spp

\begin{tabular}{|c|c|c|c|c|c|c|c|c|}
\hline \multirow[t]{2}{*}{ Antibiotic } & \multirow{2}{*}{$\begin{array}{c}\text { Disc content } \\
\text { mcg }\end{array}$} & \multicolumn{2}{|c|}{ E.coli (14) } & \multicolumn{2}{|c|}{ Klebsiella spp (05) } & \multirow{2}{*}{$\begin{array}{l}\text { Sensitive } \\
\geq \mathrm{mm}\end{array}$} & \multirow{2}{*}{$\begin{array}{c}\text { Inter } R \\
\text { mediate } \\
(\mathrm{mm})\end{array}$} & esistance \\
\hline & & Sensitive & Resistant & Sensitive & Resistant & & & $\leq \mathrm{mm}$ \\
\hline \multirow[t]{2}{*}{$\overline{\text { Co-trimoxazole }}$} & $1.25 / 23.75$ & $06(42.85 \%)$ & & & & & & \\
\hline & $08(57.14 \%)$ & $01(20 \%)$ & $04(80 \%)$ & 16 & $11-15$ & 10 & & \\
\hline \multirow{2}{*}{ Gentamicin } & 10 & $09(64.28 \%)$ & $05(35.71 \%)$ & $01(20 \%)$ & & & & \\
\hline & $04(80 \%)$ & 15 & $13-14$ & 12 & & & & \\
\hline Ciprofloxacin & 5 & $04(28.57 \%)$ & $10(71.42 \%)$ & $02(40 \%)$ & $03(60 \%)$ & 21 & $16-20$ & 15 \\
\hline \multirow[t]{3}{*}{ Levofloxacin } & 5 & $04(28.57 \%)$ & & & & & & \\
\hline & $10(71.42 \%)$ & $03(60 \%)$ & & & & & & \\
\hline & $02(40 \%)$ & 17 & $14-16$ & 13 & & & & \\
\hline Cephradine & 30 & $02(14.28 \%)$ & $12(85.71 \%)$ & ) ------ & $05(100 \%)$ & 18 & $15-17$ & 14 \\
\hline Cefoxitin & 30 & $09(64.28 \%)$ & $05(35.71 \%)$ & ) $03(60 \%)$ & $02(40 \%)$ & 18 & $15-17$ & 14 \\
\hline Ceftriaxone & 30 & $06(42.85 \%)$ & $08(57.14 \%)$ & ) $01(20 \%)$ & $04(80 \%)$ & 23 & $20-22$ & 19 \\
\hline Ceftazidime & 30 & $11(78.57 \%)$ & $03(21.42 \%)$ & $03(60 \%)$ & $02(40 \%)$ & 21 & $18-20$ & 17 \\
\hline \multirow[t]{2}{*}{ Cefepime } & 30 & $11(78.57 \%)$ & $03(21.42 \%)$ & $04(80 \%)$ & & & & \\
\hline & $01(20 \%)$ & 25 & --- & 18 & & & & \\
\hline \multirow[t]{2}{*}{ Aztreonam } & 30 & $10(71.42 \%)$ & & & & & & \\
\hline & $04(28.57 \%)$ & $01(20 \%)$ & $04(80 \%)$ & 21 & $18-20$ & 17 & & \\
\hline \multirow[t]{2}{*}{ Imipenem } & 10 & $13(92.85 \%)$ & & & & & & \\
\hline & $01(7.14 \%)$ & $05(100 \%)$ & ------- & 23 & $20-22$ & 19 & & \\
\hline Meropenem & 10 & $13(92.85 \%)$ & $01(7.14 \%)$ & $05(100 \%)$ & ------- & 23 & $20-22$ & 19 \\
\hline Netilmicin & 30 & $09(64.28 \%)$ & $05(35.71 \%)$ & $05(100 \%)$ & ------- & 15 & $13-14$ & 8 \\
\hline
\end{tabular}

Table VII

Antibiotic sensitivity of Acinetobacter spp

\begin{tabular}{|c|c|c|c|c|c|c|}
\hline \multirow[t]{2}{*}{ Antibiotic } & \multirow{2}{*}{$\begin{array}{c}\text { Disc content } \\
\text { mcg }\end{array}$} & \multicolumn{2}{|c|}{ Acinetobacter spp (11) } & \multicolumn{2}{|c|}{ Sensitive Intermediate } & \multirow{2}{*}{$\begin{array}{c}\text { Resistance } \\
\leq \mathrm{mm}\end{array}$} \\
\hline & & Sensitive & Resistant & $\geq \mathrm{mm}$ & $\mathrm{mm}$ & \\
\hline Amikacin & 30 & 08(72.72\%) & $03(27.27 \%)$ & 17 & $15-16$ & 14 \\
\hline Ciprofloxacin & 5 & $06(54.54 \%)$ & $05(45.45 \%)$ & 21 & $16-20$ & 15 \\
\hline Levofloxacin & 5 & $07(63.63 \%)$ & $04(36.36 \%)$ & 17 & $14-16$ & 13 \\
\hline Cephradine & 30 & $11(100 \%)$ & ------- & 18 & $15-17$ & 14 \\
\hline Ceftriaxone & 30 & $05(45.45 \%)$ & $06(54.54 \%)$ & 21 & $14-20$ & 13 \\
\hline Ceftazidime & 30 & $08(72.72 \%)$ & $03(27.27 \%)$ & 18 & $15-17$ & 14 \\
\hline \multirow[t]{2}{*}{ Cefepime } & 30 & 08(72.72\%) & & & & \\
\hline & $03(27.27 \%)$ & 18 & $15-17$ & 14 & & \\
\hline \multirow[t]{2}{*}{ Aztreonam } & 30 & $06(54.54 \%)$ & & & & \\
\hline & $05(45.45 \%)$ & 22 & $16-21$ & 15 & & \\
\hline Imipenem & 10 & $11(100 \%)$ & ------ & 22 & $19-21$ & 18 \\
\hline Meropenem & 10 & $11(100 \%)$ & ------ & 18 & $15-17$ & 14 \\
\hline $\begin{array}{l}\text { Piperacillin- } \\
\text { tazobactam }\end{array}$ & $100 / 10$ & $11(100 \%)$ & ------- & 21 & $18-20$ & 17 \\
\hline
\end{tabular}


Table VIII

Antibiotic sensitivity of Enterococcus spp

\begin{tabular}{lcccccc}
\hline Antibiotic & Disc content & \multicolumn{2}{c}{ Enterococcus Spp (02) } & \multicolumn{3}{c}{ Sensitive Intermediate } \\
& mcg & Sensitive & Resistant & $\geq \mathrm{mm}$ & $\mathrm{mm}$ & $\leq \mathrm{mm}$ \\
\hline Ciprofloxacin & 5 & ---- & $02(100 \%)$ & 21 & $16-20$ & 15 \\
Levofloxacin & 5 & ---- & $02(100 \%)$ & 17 & $14-16$ & 13 \\
Ampicillin & 10 & --- & $02(100 \%)$ & 17 & ---- & 16 \\
Penicillin & 10 units & ----- & $02(100 \%)$ & 15 & ---- & 14 \\
Vancomycin & 30 & $02(100 \%)$ & ----- & 17 & $15-16$ & 14 \\
Gentamycin & 10 & ---- & $02(100 \%)$ & 15 & $13-14$ & 12 \\
Linezolid & 30 & $02(100 \%)$ & ----- & 23 & $21-22$ & 20 \\
\hline
\end{tabular}

Table IX

Antibiotic sensitivity of Staphylococcus spp

\begin{tabular}{|c|c|c|c|c|c|c|}
\hline \multirow[t]{2}{*}{ Antibiotic } & \multirow{2}{*}{$\begin{array}{c}\text { Disc content } \\
\text { mcg }\end{array}$} & \multicolumn{2}{|c|}{ Staphylococcus Spp (02) } & \multicolumn{2}{|c|}{ Sensitive Intermediate } & \multirow{2}{*}{$\begin{array}{c}\text { Resistance } \\
\leq \mathrm{mm}\end{array}$} \\
\hline & & Sensitive & Resistant & $\geq \mathrm{mm}$ & $\mathrm{mm}$ & \\
\hline Amikacin & 30 & $02(100 \%)$ & $\begin{array}{l}----- \\
\end{array}$ & 17 & $15-16$ & 14 \\
\hline Cephradine & 30 & $02(100 \%)$ & ------ & 18 & $15-17$ & 14 \\
\hline Cefepime & 30 & $02(100 \%)$ & ------ & 18 & $15-17$ & 14 \\
\hline Cefoxitin & 10 & $02(100 \%)$ & ---- & 18 & $15-17$ & 14 \\
\hline Cloxacillin & 05 & $02(100 \%)$ & ------- & 22 & ---- & 21 \\
\hline Vancomycin & 30 & $02(100 \%)$ & ------ & 15 & ---- & ---- \\
\hline Gentamycin & 10 & $02(100 \%)$ & ------ & 15 & $13-14$ & 12 \\
\hline Linezolid & 30 & $02(100 \%)$ & ----- & 21 & ----- & 20 \\
\hline
\end{tabular}

\section{Discussion}

Bloodstream infection is a challenging problem, and sometimes, it may be life threatening; therefore, timely detection, identification, and antimicrobial susceptibility testing of blood-borne pathogens are one of the most important functions of diagnostic microbiology laboratory ${ }^{1}$.

Due to wide variations in bacterial drug resistance, results of studies and reports in one region or in a period of time are not necessarily true for other regions or periods of time ${ }^{13}$. They are related with a series of social, environmental and technological changes ${ }^{14}$.

In the developing countries like Bangladesh, physicians prescribe antimicrobial more than the actual need, all kinds of antibiotics are easily available over the counter and anybody can buy drugs without physician's prescription are responsible for developing pool of resistant bacteria as well as negative results of blood culture $^{15}$.

In this study, $12.77 \%$ bacteria were isolated, that is almost same (14.38\%) found in another private diagnostic centre in Dhaka ${ }^{16}$. In another study from Bangladesh, the recovery rate of microbial pathogens among blood cultures was found to be $11.6 \%{ }^{17}$. Isolation rate of $20 \%$ was reported from a study done in $\mathrm{Nepal}^{18}$. This shows that there may be inter country variation.

In the present study, culture positive rate in adult patients was $57.14 \%$ which correlate with the study done by Wadud et al in $2009^{15}$ which has revealed significantly high rates of blood culture positivity in adult patients (63.51\%).

Slightly higher isolation rate in children was reported from Children's Hospital at Myanmar, 
where isolation rate in was found as $54.2 \%{ }^{19}$. Similar study from Japan found blood culture positivity among paediatric age group as $53.6 \%{ }^{20}$, which are contradictory to this study where isolation rate in children was $45(42.85 \%)$. The reasons behind this outcome might be the selection criteria of samples. We included all samples (indoor and outdoor) came to the study laboratory irrespective of age or may be due to empirical use of broad-spectrum antibiotics before collection of blood samples.

In this study, men had high culture positivity as compared with women. The result was consistent with the study done by Kaur and Singh $(2014)^{21}$ who reported high culture positivity in $65.22 \%$ men. The finding was also similar to study by Hussein et al. (2005) ${ }^{22}$ that reported $66.66 \%$ positivity in men and $33.33 \%$ in women. Men are the active and are the main earning members of most families, so they are more privileged to visit physician chamber for treatment. However, Zenebe et al. $(2011)^{2}$ reported more high culture positivity in women, $59.2 \%$, than men, $40.8 \%$, in their study.

In the present study most common isolates are Salmonella Typhi (56.19\%) followed by Salmonella paratyphi (10.47\%). In another study in Dhaka, Salmonella spp was the single most common pathogen $(72.7 \%)$ among the recovered isolates ${ }^{16}$. A Study in BSMMU, Dhaka demonstrates that Salmonella Typhi and Salmonella paratyphi isolation rate as $77.97 \%$ and $22.02 \%$ respectively ${ }^{23}$. The high rate of isolation of enteric fever in these studies is probably as people consume contaminated water from sewage system. However, the prevalence may be much higher, but empirical use of antibiotic hinders their growth in vivo.

In this study, Salmonelle Spp shows 100\% sensitivity to Ceftriaxone and Cefixime. Exceptionally, Nalidixic acid showed low sensitivity (05.31\%). In a study in Pakistan show similar sensitivity pattern ${ }^{24}$. These findings were in agreement to a study done in Dhaka Medical College, 201725. Although third generation Cephalosporin, Ceftriaxone is effective, the cost and route of administration makes Ceftriaxone less appropriate for therapeutic use in developing countries such as Bangladesh. Many Salmonella strains seem to be sensitive to fluoroquinolones in vitro (Table V), they do not work as good in vivo because most of them are nalidixic acid resistant due to mutation in QRDR region of gyrA gene ${ }^{26}$.

We showed over $80 \%$ susceptibility of Salmonella to both Chloramphenicol and Co trimoxazole. Decrease resistance to these antibiotics for Salmonella was similar to studies from India ${ }^{27}$ and $\mathrm{Nepal}^{28}$. As in many developing countries like Bangladesh conventional first-line drug (Chloramphenicol and Co trimoxazole) have been restricted for almost two decades due to development of resistant strains. This may be due to reduction in the antimicrobial pressure on these organisms cause lost their resistance genes. Studies have shown that if antimicrobial is withheld for a long period the organisms lose their resistance gene. Thus these findings may be helpful to revise current empirical therapy policies for enteric fever. These findings were agreed to a study done in Dhaka Medical College, $2017^{24}$.

In this study, rate of isolation of Escherechia coli was $13.33 \%$ and Klebsiella spp is $04.76 \%$. . In a study in Myanmar, where Escherichia coli was $12.3 \%$ that is almost same to our findings ${ }^{18}$. More than $90 \%$ E. coli and $100 \%$ Klebsiella spp. were sensitive to Imipenem and Meropenem. The results for Klebsiella spp. were consistent with the study done by Saghir et al. $(2009)^{29}$ who reported $96 \%$ sensitivity. The results of $E$. coli and Klebsiella spp. were also consistent with the study done by Jyothi et al. $(2013)^{30}$ who reported sensitivity of $93 \%$ for $E$. coli and Klebsiella spp.

In the present study, ceftriaxone showed $42.85 \%$ sensitivity to E. coli, $20 \%$ to Klebsiella spp. These findings for E. coli and Klebsiella spp. were consistent with the studies done by Fayyaz et al. (2013) ${ }^{31}$ who reported $28 \%$ and $22.44 \%$ sensitivity respectively. The observation of ceftriaxone resistance pattern is suggestive of the fact that $57.14 \% \mathrm{E}$. coli and $80 \%$ of Klebsiella spp. isolates were extended spectrum beta-lactamase (ESBL) producers.

In the present study only $01.90 \%$ Staphylococcus aureus was isolated. Similar low 
$(00.28 \%)$ isolation rate was observed in another study in Bangladesh ${ }^{15}$. However, in a study in India the isolation rate was high $13(52 \%){ }^{1}$. The low level of isolation of Staphylococcus may be that most patients start antimicrobials from the very beginning of any symptoms presentation and most of these organisms are sensitive to most of the antimicrobials.

In our study, all the Staph aureus were 100\% sensitive to Vancomycin, Linezolid, Cefepime, Cefoxitin. This correlates with the sensitivity done in India ${ }^{1}$.

Isolation of Enterococcus spp in this study was 01.90\% and all Enterococcus spp showed 100\% sensitivity to Vancomycin, Linezolid and 100\% resistant to Ciprofloxacin, Penicillin. This result is consistant with the sensitivity done by Nikita et al (2016) ${ }^{1}$.

There was variation in the antibiotic sensitivity rate of various organisms isolated in the present study when compared to different past studies. This may be due to the fact that sensitivity of

organisms to antibiotics is variable and depends upon prevalence of strains, antibiotics use, and its resistance patterns in a particular area.

\section{Conclusion}

Our study result showed the presence of invasive bacterial pathogens with high rate of resistance to most commonly used antibiotics used to treat bacterial infections. Therefore, timely investigation of bacterial flora of the blood stream infections and monitoring of their antibiotic resistance pattern plays an important role in reduction of the incidence of blood stream infections.

\section{References}

1. Vasudeva N, Nirwan P S and Shrivastava P. Bloodstream infections and antimicrobial sensitivity patterns in a tertiary care hospital of India. Ther Adv Infectious Dis. 2016; 3(5): $119-127$.

2. Zenebe T, Kannan S, Yilma D, Beyene G. Invasive bacterial pathogens and their antibiotic susceptibility patterns In Jimma University Specialized Hospital, Jimma, and Southwest Ethiopia. Ethiop J Health Sci. $2011 ; 21: 1-8$

3. Karlowsky, J.A., M.E. Jones, D.C. Draghi, C. Thornsberry, D.F. Sahm and G.A. Volturo. Prevalence and antimicrobial susceptibilities of bacteria isolated from blood cultures of hospitalized patients in the United States in 2002. Ann. Clin. Microbiol.2004; 3: 7-7.

4. Hall KK, Lyman JA. Updated review of blood culture contamination. Clinical microbiology reviews. 2006; 19(4):788-802.

5. Yagupsky P, Nolte FS. Quantitative aspects of septicaemia Clin Microbiol.1990; 3:269-79.

6. Gohel K, Jojera A, Soni S, Gang S, Sabnis R, Desai M. Bacteriological profile and drug resistance patterns of blood culture isolates in a tertiary care nephrourology teaching institute. Biomed Res Int. 2014; 2014:153-747.

7. Deen J, Seidlein L, Andersen F, Elle N, White NJ , Lubell Yoel. Community-acquired bacterial bloodstream infections in developing countries in south and Southeast Asia: a systematic review.2012; 12(6): p480-487.

8. Kang C-I, Kim S-H, Park WB, et al. Bloodstream infections caused by antibiotic-resistant gramnegative bacilli: risk factors for mortality and impact of inappropriate initial antimicrobial therapy on outcome. Antimicrobial Agents and Chemotherapy. 2005; 49(2):760 766.

9. Kollef $\mathrm{MH}$. Inadequate antimicrobial treatment: an important determinant of outcome for hospitalized patients. Clin. Infect. Dis. 2000; 31:S131- S138.

10. Leone, M., A. Bourgoin, S. Cambon, M. Dubuc, J. Albanese, and C. Martin. Empirical antimicrobial therapy of septic shock patients: adequacy and impact on the outcome. Crit. Care Med. 2003; 31:462-467.

11. Forbes, B.A., D.F. Sahm, A.S. Weissfeld, 2002. Bailey and Scotts Diagnostic Microbiology: A Textbook for Isolation and Identification of Pathogenic Microorganisms. 11th Edn., The Mosby Company, St. Louis, ISBN-13: 978-0815125358, pp: 378-422.

12. Clinical and Laboratory Standards Institute (CLSI). Performance Standards for Antimicrobial Susceptibility Testing. 27th ed. CLSI supplements M100. Clinical and Laboratory Standards Institute, 950 West Valley Road, Suite 2500, Wayne, Pennsylvania 19087 USA, 2017.

13. Huang, S.S., B.J. Labus, M.C. Samuel, D.T. Wan, A.L. Reingold. Antibiotic resistance patterns of bacterial isolates from blood in San Francisco County, California, 1996-1999. Emerg. Infect. Dis.2002; 8: 195-201.

14. Cohen, M.L. Epidemiological factors influencing the emergence of antimicrobial resistance. Ciba Found. Symp., 1997; 207: 223-231.

15. Mamun KZ, Tabassum S, Shears P, Hart CA. A survey of antimicrobial prescribing and dispensing practices 
in rural Bangladesh. Mymensingh Med J. 2006; 15 (1); 81-84.

16. Wadud ABMA, Khalil M1, Shamsuzzaman AKM et al. Bacteriological profiles of Blood culture isolates by BacT/ALERT 3D automated system. Journal of Shaheed Suhrawardy Med Col.2009; 1(2).

17. Saha SK, Baqui AH, Hanif M, Darmstadt GL, Ruhulamin M, Nagatake T. Typhoid fever in Bangladesh: implications for vaccination policy. Pediatric Infectious Disease Journal 2001; 20(5):521524

18. Shrestha P, Das BK, Bhatta NK, et al. Clinical and Bacteriological Profiles of Blood Culture Positive Sepsis in Newborns. J. Nepal Paediatr.Soc 2008; 27(2): 64-67.

19. Than Nu Shwe, Mar Mar Nyein, Wut Yi, Aung Mon. Blood culture isolates from children admitted to Medical Unit III, Yangon Children's Hospital. Southeast Asian J Trap Med Public.1998; 764-771.

20. Niimi Yoshihiro, Saito Takako, Izumo Taeko. Isolation of microorganisms from blood cultures during 8 years at Sakai Municipal Hospital Frequency of isolation, number of samples per Bacteriological profiles of Blood culture isolates by BacT/ALERT 3D automated system case, and CVC-related bacteremla Sakai Municipal Hospital Medical Journal 2004; 7: 64-71.

21. Kaur, A. and Singh, V. Bacterial isolates and their antibiotic sensitivity pattern in clinically suspected cases of fever of unknown origin. JK Science. 2014; 16: $105-109$

22. Hussein, A., Sayed, A., Mohamed, A. Seroepidemiological study on human brucellosis in Assiut Governorate. Egypt J Immunol.2005; 12: 49-56.

23. Saleh AA, SattarANI, Ahmed S, Miah MRA. Antibiotic sensitivity pattern of Salmonell species isolated by blood culture in Bangabandhu Sheikh Mujib Medical University, Dhaka. BJMM 2008; 2(2); 22-36.

24. Qamar FN, Azmatullah A, Kazi AM, Khan E, Zaidi AKM. A three-year review of antimicrobial resistance of Salmonella enteric serovars Typhi and Paratyphi A in Pakistan. J infect Dev Ctries. 2014; 8(8):981986.

25. Suman MA, Siddique MA, Shamsuzzaman SM, Khandakar AR. Re-Emergence of Susceptibility to Conventional First Line Drugs in Salmonella Typhi and Paratyphi a isolated from Enteric Fever Patients in a Tertiary Care Hospital of Northern Bangladesh. Bangladesh J Med Microbial. 2017; 11(01): 03-05.

26. Suman MA, Siddique MA, Shamsuzzaman SM et al. Detection of mutated gyrA gene from nalidixic acid resistant Salmonella typhi and paratyphi A isolated from enteric fever patients in a tertiary care hospital in Bangladesh. Bangladesh J Med Microbial. 2016; 10(01): 03-07.

27. Srirangaraj S, Kali A, Charles MVP. A study of antibiogram of Salmonella enteric serovars Typhi isolates from Pondicherry, India. AMJ. 2014; 7(4): 185-190.

28. Chand HJ, Rijal KR, Neupane B, Sharma VK and Jha B. Re-Emergence of susceptibility to Conventional first line drugs in Salmonella isolates from enteric fever patients in Nepal. $\mathrm{J}$ infect Dev Ctries. 2014; 8(11): 1483-1487.

29. Saghir, S., Faiz, M., Saleem, M., Younus, A. and Aziz, H. (2009) Characterization and anti-microbial susceptibility of gram-negative bacteria isolated from bloodstream infections of cancer patients on chemotherapy in Pakistan. Indian J Med Microbiol. 2009; 27:341-347.

30. Jyothi, P., Basavaraj, M. and Basavaraj, P. Bacteriological profile of neonatal septicemia and antibiotic susceptibility pattern of the isolates. J Nat Sci Biol Med. 2013; 4: 306-309.

31. Fayyaz, M., Mirza, I., Ikram, A., Hussain, A., Ghafoor, T. and Shujat, U. Pathogens causing blood stream infections and their drug susceptibility profile in immunocompromised patients. J Coll Physicians Surg Pak. 2013; 23: 848-851. 